Western University

Scholarship@Western

Aboriginal Policy Research Consortium International (APRCi)

10-7-2009

\title{
Community-based Suicide Prevention Research in Remote On-Reserve First Nations Communities
}

Corinne A. Isaak

Mike Campeau

Laurence Y. Katz

Murray W. Enns

Brenda Elias

See next page for additional authors

Follow this and additional works at: https://ir.lib.uwo.ca/aprci

Part of the Community-Based Research Commons, and the Other Mental and Social Health Commons

Citation of this paper:

Isaak, Corinne A.; Campeau, Mike; Katz, Laurence Y.; Enns, Murray W.; Elias, Brenda; and Sareen, Jitender, "Community-based Suicide Prevention Research in Remote On-Reserve First Nations Communities" (2009). Aboriginal Policy Research Consortium International (APRCi). 250.

https://ir.lib.uwo.ca/aprci/250 
Authors

Corinne A. Isaak, Mike Campeau, Laurence Y. Katz, Murray W. Enns, Brenda Elias, and Jitender Sareen 


\title{
Community-based Suicide Prevention Research in Remote On-Reserve First Nations Communities
}

\author{
Corinne A. Isaak • Mike Campeau • Laurence Y. Katz • \\ Murray W. Enns • Brenda Elias • Jitender Sareen • \\ Swampy Cree Suicide Prevention Team
}

Received: 28 May 2009 / Accepted: 16 September 2009/

Published online: 7 October 2009

(C) Springer Science + Business Media, LLC 2009

\begin{abstract}
Suicide is a complex problem linked to genetic, environmental, psychological and community factors. For the Aboriginal population more specifically, loss of culture, history of traumatic events, individual, family and community factors may also play a role in suicidal behaviour. Of particular concern is the high rate of suicide among Canadian
\end{abstract}

The Swampy Cree Suicide Prevention Team* (listed alphabetically) is consist of the following: Shay-Lee Belik is affiliated to Departments of Psychiatry and Community Health Sciences, University of Manitoba, Winnipeg, Manitoba, Canada.

Catherine Cook is affiliated to Department of Community Health Sciences, and Manitoba First Nations Centre for Aboriginal Health Research, Department of Community Health Sciences, University of Manitoba, Winnipeg, Manitoba, Canada.

Brian Cox is affiliated to Departments of Psychiatry, Community Health Sciences, and Psychology, University of Manitoba, Winnipeg, Manitoba, Canada.

Natalie Mota is affiliated to Departments of Psychiatry, and Department of Community Health Sciences, University of Manitoba, Winnipeg, Manitoba, Canada.

Garry Munro is affiliated to Cree Nation Tribal Health, Swampy Cree Tribal Council, The Pas, Manitoba, Canada. Briana Melia is affiliated to Department of Psychology, University of Winnipeg, Winnipeg, Manitoba, Canada.

John O'Neil is affiliated to Department of Community Health Sciences, Manitoba First Nations Centre for Aboriginal Health Research, Department of Community Health Sciences, University of Manitoba, Winnipeg, Manitoba, Canada and Faculty of Health Sciences, Simon Fraser University, Burnaby, British Columbia.

C. A. Isaak $\cdot$ L. Y. Katz $\cdot$ M. W. Enns

Department of Psychiatry, University of Manitoba, Winnipeg, Manitoba, Canada

J. Sareen

Departments of Psychiatry, Community Health Sciences and Psychology, University of Manitoba, Winnipeg, Manitoba, Canada

M. Campeau

Cree Nation Tribal Health, Swampy Cree Tribal Council, The Pas, Manitoba, Canada

B. Elias

Department of Community Health Sciences, University of Manitoba, Winnipeg, Manitoba, Canada 
Aboriginal youth. While the need to develop interventions to reduce suicidal behaviour for First Nations on-reserve populations is evident, there may be an element of distrust of researchers by Aboriginal communities. Furthermore, research in mental health and specifically suicide is much more sensitive than studying medical illnesses like diabetes. Clearly, this issue requires a unique and insightful approach. While numerous suicide prevention/intervention plans and guidelines have been published specifically for work involving Aboriginal people, the literature lacks a comprehensive discussion of the methodological and logistical issues faced by research teams and Aboriginal communities attempting to develop culturally-grounded and community-specific suicide prevention and intervention strategies. This paper outlines the research process, key challenges and lessons learned in a collaborative University-First Nations suicide prevention project conducted with eight north-western Manitoba First Nations communities (Canada).

Keywords Aboriginal · First Nations · Suicide prevention · Suicide intervention · Participatory action $\cdot$ Community-based

\section{Introduction}

Suicide is a complex issue that may be linked to genetic, environmental, psychological, and community factors (Mann et al. 2005). Suicidal behaviour among the Canadian Aboriginal ${ }^{1}$ population is of particular concern as rates of completed suicide are two to three times higher than in the non-Aboriginal population and Aboriginal youth suicide rates are five to six times higher as compared to that of non-Aboriginal youth (Health Canada 2003). Thus, suicide, especially among Canadian Aboriginal youth is a significant concern (Kirmayer et al. 1998, Malchy et al. 1997, Sigurdson et al. 1994). Established risk factors for suicide in the global Aboriginal population are community alienation, substance abuse, psychiatric problems, physical abuse (Kirmayer et al. 2000), disconnection with cultural history (Chandler and Proulx 2006), childhood separation and loss (Boothroyd et al. 2001), lack of interpersonal support (Wexler and Goodwin 2006), lack of social capital and community participation and trust (Mignone and O'Neil 2005), exposure to suicide attempts or completions (Boothroyd et al. 2001; Grossman et al. 1991; Kirmayer et al. 1998), cultural stress and a weakening of belief systems and spirituality (RCAPa 1995).

While suicide rates among Canadian Aboriginal peoples are dramatically higher when compared to other Canadians, evidence now suggests that in some Aboriginal communities, suicide is virtually unheard of (Chandler and Lalonde 1998) and that numerous protective factors are evident. Such factors as engagement in community practices and rehabilitation (Chandler and Lalonde 1998), good school performance, regular church attendance

\footnotetext{
"The term "Aboriginal" includes three distinctive groups in Canada: Indian, Métis and Inuit peoples (Constitution Act 1982; Statistics Canada 2003). The term "First Nations" refers to descendants of the original inhabitants of Canada, and is used in place of "Indian" which is a colonial term.
}

B. Elias

Manitoba First Nations Centre for Aboriginal Health Research, Department of Community Health Sciences, University of Manitoba, Winnipeg, Manitoba, Canada

C. A. Isaak $(\square)$

PZ432-771 Bannatyne Avenue, Winnipeg, Manitoba R3E 3N4, Canada

e-mail: cisaak@hsc.mb.ca 
(Kirmayer et al. 2000), preserved ties to cultural past and local control (Chandler and Proulx 2006), high community social networks (Mignone and O'Neil 2005), and enhanced adult-youth relation and communication (Wexler and Goodwin 2006) appear to protect individuals, families and communities from this experience.

The need for action to reduce suicidal behaviour in the Aboriginal population is well recognized and an abundance of information has been published ranging from suicide research guidelines and reports (Aboriginal Healing Foundation 2007; Health Canada 2003; Kirmayer et al. 1999; RCAPb 1995; White and Jodoin 2003; White 2005; World Health Organization 2000) to community, regional and national suicide prevention planning documents (Health Canada 2007; Masecar 2007; Manitoba Healthy Living 2008; National Aboriginal Health Organization (NAHO) 2005). Policy-makers are in need of evidencebased interventions in this population; however, such information is not currently available. We speculate that this may be due to the many challenges in conducting mental health and suicide research in Aboriginal process.

What is lacking in the literature is a comprehensive discussion of the methodological and logistical issues faced by research teams and Aboriginal communities attempting to develop culturally-grounded and community-specific suicide prevention and intervention strategies. This paper will address this gap by discussing the way a university-First Nations tribal organization team and Manitoba First Nations communities collaborated to develop and implement a suicide prevention research project. We first summarize the research process and approach taken. We then describe some of the key challenges we faced during the initiation and implementation stages of the project and the lessons we learned along the way to successfully launch our collaborative intervention research program.

\section{The Research Process}

In Canada, research has shown that more Aboriginal people die by suicide than those in the general population. While numerous risk and protective factors have been identified and a host of suicide prevention strategies developed specific to the Aboriginal population, the rate of suicidal behaviour in Aboriginal communities still remains a concern in Manitoba and Canada generally. So why suicidality persists, what would be an effective and sustainable suicide prevention strategy for a specific group of First Nations people, and what is the best approach to learn, understand, or research these questions remains unanswered. As well, can the approach developed for this group of First Nations people be applied to other tribal groups or to the general population?

Today, participatory research is among the many ethical requirements for researchers conducting Aboriginal health research in Canada. The Canadian Institutes of Health Research (CIHR) developed the CIHR Guidelines for Health Research Involving Aboriginal People which includes a clause indicating that "communities should be given the option of a participatory-research approach" (CIHR 2007; p.19). Given the concerns around research among Aboriginal communities and the development of these guidelines, health researchers, medical professionals, mental health and social workers, and policy makers must be aware of the cultural and personal environment of First Nations people in the context of suicide. In order for effective and sustainable culturally-grounded and community specific strategies to be developed, those who live and work in these First Nations communities must be involved in the development of the research project as well as any planned suicide prevention and intervention strategies. It is with these principles in mind that the Swampy Cree Suicide Prevention Team was developed. 


\section{The Swampy Cree Suicide Prevention Team and Research Project: Its Development}

Prior to the development of the Swampy Cree Suicide Prevention project, suicide research in Manitoba with First Nations communities was nonexistent. In order to understand the possible issues and challenges of mental health and suicide prevention research with Aboriginal peoples, several key research groups who had worked with Aboriginal communities in the United States (Jan Beals) and Australia (Frank Deane) were consulted to learn of their experiences and seek advice regarding this type of work.

In the following section we describe the formation of a partnership and the development of a research process that resulted in a successfully funded 5 year (2007-2012) research project titled From risk factors to culturally sensitive interventions: A programmatic approach to Aboriginal suicide as outlined in Katz et al. (2006).

From risk factors to culturally sensitive interventions emerged as a community-based participatory action research (PAR) project that equally engages the community in the research process from its inception and provides control over the research (Cornwall and Jewkes 1995). The intent of this project is consistent with PAR in that the central purpose of participatory action research is to develop knowledge that is useful, practical and contributes to improved well-being of the people and community involved in the research (Reason and Bradbury 2001).

This project is a collaborative partnership between a group of researchers in the Departments of Psychiatry and Community Health Sciences at the University of Manitoba and members of Cree Nation Tribal Health, a health organization overseeing the needs of the First Nations communities within the Swampy Cree Tribal Council area. The Swampy Cree Tribal Council represents eight First Nations communities scattered across northwestern/ central Manitoba, geographically located between 50 and 55 degrees latitude (Indian and Northern Affairs Canada 2009; Swampy Cree Tribal Council 2009). The Swampy Cree communities are diverse in population size and remoteness as well as in their access to mental health services. The registered on-reserve populations (based on Canada Census 2001) in the various Swampy Cree communities range from approximately 200 to 3,000 people, with a median reported age between 17.2 and 22.0 years (Indian and Northern Affairs Canada 2009).

Critical to the establishment of the partnership between the university-based researchers and the First Nations tribal council was a long-standing pre-existing relationship between several researchers from the Manitoba First Nations Centre for Aboriginal Health Research (a research unit in the Department of Community Health Sciences, Faculty of Medicine) and the Swampy Cree Tribal Council and Cree Nation Tribal Health Centre (O'Neil et al. 2005). This research endeavor was facilitated through the Assembly of Manitoba Chiefs (AMC) - a Manitoba regional tribal body that represents the interests of 64 Manitoba First Nations Communities (AMC 2009).

Because of this existing relationship, the University of Manitoba researchers and members of Cree Nation Tribal Health (organization responsible for delivering health services to the Swampy Cree communities) were able to enter into discussion to explore the possibility of conducting a suicide prevention project in and with the eight Swampy Cree communities. Following general approval, ethical consent for the project was given by the University of Manitoba Research Ethics Board. In accordance with the Canadian Institutes of Health Research (CIHR) guidelines for community consent, the project was also approved by the Swampy Cree Tribal Council Board of Directors, the Chief and Council of each of the communities as well as Cree Nation Tribal Health, (CIHR 2007).

The initial stage or aim of the project was to have Indigenous knowledge guide understanding of suicidal behaviour in the Swampy Cree First Nation communities. To that end, qualitative methods in keeping with an Indigenous approach were used to explore the 
following research question: What are Aboriginal perspectives on suicide, suicidal behaviour and suicide prevention? (Katz et al. 2006). Indigenous research approaches have been defined as a framework, a broader epistemology which goes beyond methods; however the methods used may include qualitative methods that allow for storytelling and personal narratives (Grande 2008; Lavallée 2009). Western qualitative methods such as focus groups and individual interviews were used in the current project to allow participants to tell their stories and provide their perspectives regarding suicide and its related issues. Qualitative methods are a key research method for discovering underlying perceptions and values (Lucasey 2000). The foundation of qualitative research is to learn from the participants, to highlight the uniqueness of the individual or community and to explore the variation in their experiences (Krefting 1991).

In order to understand suicidal behaviour within a First Nations community context, it is essential to gain an Indigenous understanding, and in this case an understanding specific to the Swampy Cree communities. To ground the qualitative approach within Indigenous knowledge, the first endeavor was a meeting arranged by Cree Nation Tribal Health and held in one of the Swampy Cree communities in May of 2007. At that meeting, university researchers were asked to present on the key aspects of the project and twelve Swampy Cree members including an elder, youth and community health authority employees shared their concerns, histories and ideas about suicide behavior in their communities. A round table approach was used where each community member took turns sharing their knowledge, and the university researchers joined in this approach as they shared their knowledge. Once everyone shared their understanding of the issue, the logistics of implementing the project was discussed, including how to best document and collect Indigenous knowledge of suicide behavior. The following perspective offered by one the attendees summarizes the need for gaining an Aboriginal perspective and for community involvement in the project:

Health worker: [The] qualitative piece is very important and the community has to own it, see what is happening and to understand why it is happening. These problems are our problems... The people have to own it.

The support for using an Indigenous-led qualitative approach when developing research projects with Aboriginal peoples has been supported by other Aboriginal groups and has resulted in successful projects (O'Neil et al. 1998).

A First Nations member, Mike Campeau, who is acknowledged and recognized for his leadership, commitment to addressing mental health issues, and experience working with all the communities was invited to become the project facilitator. His role is to assist with the development of the project, introduce researchers to the Swampy Cree communities, support the university-based investigators during the data collection activities, and to conduct some aspect of the research in these communities. The project facilitator also played a pivotal and equal role in the development of the qualitative interview guide. The guide was developed using an iterative process with extensive input from all university and community team members. This iterative process demonstrated the differences between the university researchers and the community approach to asking questions and by making this difference apparent, an interview guide that is more in tune with First Nations ways of asking questions was developed (Table 1). While signed consent to undertake research is standard for most university research, the project facilitator helped bridge this legal process with community norms around sharing knowledge.

The importance of "visiting" was also recognized in the research process. Members of the research team visited each of the eight communities for several days and during this visit a community gathering and meal was organized in order for community members to 
Table 1 Qualitative Interview Guide Questions

1) Please tell me a little bit about your community

2) Can you tell me about family life here?

3) What are some issues /problems that may affect people here?

4) For people who can't rely on their family to go to when they are feeling upset (sad, angry, stressed or have thoughts of trying to harm themselves), who would they have to turn to for help?

5) In your community, how big of a problem do you think it is that people may be trying to harm themselves or actually kill themselves?

6) From what you know, what are some of the reasons that a person might consider harming or killing themselves?

7) What happens in your community when a person kills themselves? (if not in your community, what have you heard happens in other communities)?

8) What kinds of helpful programs are already happening in the community (to prevent people from harming or killing themselves)?

9) In what way is the health center or nursing station involved in providing help? In what way is the school involved in helping youth?

10) What are some of the roadblocks that prevent people from going to mental health councilors or support groups? (e.g., privacy, stigma, location)

11) What would help to develop healthy communities and healthy families?

a. What can be done in the schools?

b. What can be done within the community?

12) What would help to keep people from thinking about harming or killing themselves?

a. What can be done in the schools?

b. What can the community do?

13) What would help people who have already tried to harm or kill themselves (attempted suicide)?

a. What can the Health Centre/Nursing Station, Local Hospitals do?

b. What can the Swampy Cree Tribal Health Centre do?

c. What do you think would be helpful in a treatment program?

14) What are the signs of a healthy and happy community?

15) Is there anything more you would like to add?

16) Do you have suggestions of others who may be interested in an interview?

become acquainted with the researchers in an informal manner as opposed to a formal presentation approach which does not allow for engaging community members through a process of sharing. At these gatherings, team members discussed the project over a meal and then after creating a relationship through sharing they were able to conduct interviews with a total of 136 Swampy Cree community members. Preliminary results from the qualitative interviews highlight family strength and community connectedness in times of crisis, concerns such as drug and alcohol abuse, and the need for enhanced suicide knowledge and support, parenting and youth programs, and inclusion of cultural/traditional activities for the development of healthy communities.

Another way to create a powerful bond with the community and to ensure the success of these gatherings was by employing community liaisons on a term basis. In each community, a community liaison organized and facilitated the community gatherings and recruited community members for interviews. The community liaisons included community health representatives (CHRs), Brighter Futures/Building Healthy Communities workers (BFI/ BHC), National Native Alcohol and Drug Abuse Program workers (NNADAP) or community wellness or mental health workers. 
Community advisory councils have been developed within each Swampy Cree community. These councils will help to lead the development and implementation of suicide prevention strategies in each community. The advisory councils are made up of community health and social workers, councilors, justice personnel, educators, clergy, elders and youth. Members of the advisory councils are invited to two-day meetings where discussions are held regarding existing and required suicide prevention and intervention programs and activities specific to each community (see Table 1 questions 8,9 \& 11-13). During the 2-day meetings, members of the advisory councils are also given a half-day suicide awareness training called safeTALK (LivingWorks Education Inc. 1991).

Annual meetings are also held between the university and community research team and other members of the Swampy Cree communities in order to continue planning and to provide feedback on the research program.

\section{Key Challenges}

\section{Research in Aboriginal Communities}

Although a university-First Nations partnership had already been established, as with any research project, challenges will inevitably arise. For some Aboriginal communities, even the word 'research' or 'researcher' may invoke thoughts of mistrust of researchers and the phrase "researched to death" is all too familiar. Research may be considered an imposition on their communities, irrelevant, unnecessary or even colonialistic (Denzin and Lincoln 2008; Elias et al. 2004). Trimble (2008) speaks to this issue in his commentary regarding iterant researchers with North American Indian communities.

Increasingly, many communities are becoming concerned about the presence of "outside" researchers; many are intolerant and unforgiving of past research efforts. The once popular and widely used "safari-scholar" approach to research is fading from acceptance and "one stop data mining" by itinerant researchers is no longer acceptable (Trimble 2008; p. 380).

Within the Canadian context, similar sentiments have been voiced by Aboriginal people participating in consultation workshops across the country regarding the feasibility of a national longitudinal Aboriginal survey. "Aboriginal communities have been researched to death" (O'Neil et al. 1998; p. 232; First Nations and Inuit Regional Health Survey National Steering Committee 2000). More recently, the following phrase was used in a letter of correspondence from one of the Swampy Cree communities following a focus group discussion with the Swampy Cree Suicide Prevention Team:

It is understood that Aboriginal peoples are the most studied and researched people in Canada. We have been under the microscope for too long. If the researchers are open to take the journey with us, then it becomes a process where we are working together, not that we are doing all the work and the researchers are cold-hearted non-participant observers. An opinion was offered by one of our team [group] that we have been "studied to death", when asked about the causes of suicide.

An additional matter of concern regarding research in First Nations communities was expressed in a local weekly Aboriginal community newspaper, where the Swampy Cree Suicide Prevention project was introduced and readers were invited to comment. Some readers questioned whether there was a need for more research on suicide in First Nations communities and added 
that "the causes for suicide are obvious" (Grassroots News, June 17 2008). Members of the research team representing Cree Nation Tribal Health urged researchers to respond, which resulted in a team-developed letter to address this concern and explain the project in more detail, specifically the partnership with the Swampy Cree communities and Cree Nation Tribal Health and the ongoing nature of the project. In the letter, it was also stated that as a research team we disagreed with the statement regarding the obvious causes of suicide and that in fact suicide is a complex problem that is linked to numerous individual, family, community and cultural factors, not only in Aboriginal populations, but across the world (Sareen et al. 2008). The letter was published in a later issue of the newspaper (Grassroots News, September 9 2008). First Nations organizations have responded to the issue of research in their communities by establishing a mechanism of self government over health information known as the OCAP principles of ownership, control, access, and possession of health information (Schnarch 2004).

\section{Migration of Community Health Staff}

Another key challenge we experienced during the initiation of the qualitative stage of the project was the frequent migration of health directors, mental health, National Native Alcohol and Drug Abuse Program (NNADAP) and community health workers into different work positions or communities. As indicated earlier, community liaisons acted as contact persons between the research team and First Nations community. These people were a vital part of our entry into the communities. Along with liaisons, other community health workers and health directors were sometimes involved in the initiation of the research work within their communities. When a relationship has been established with a community contact, however limited, it becomes difficult to begin again to establish new relationships. There were numerous occasions where our community liaisons would suddenly take a different position and could no longer act as a liaison for the project, or would leave from the community making it difficult to plan for details of the community visits. Connecting with new liaisons required diligence, persistence and many telephone conversations on the part of the research team. In some cases, it proved more effective to discuss the project with the health director who then could suggest a replacement liaison.

\section{Participant Recruitment}

Recruitment for the qualitative interviews was another challenge in some communities. In some cases our liaisons had already organized a list of people who had volunteered to be interviewed, prior to our visit to their community which was extremely helpful. In other cases, much of the recruitment work had to be done by the researchers. Personal visits to community health and band offices by researchers to recruit participants resulted in limited success in some communities. Snowball sampling, in which study participants recommend others for involvement was helpful in other communities (Morse and Richards 2002; Patton 2002). In some communities there was still a level of resistance to the research project which may have slowed recruitment in these communities. A key to successful recruitment was the involvement of our community liaisons. In some communities these relationships had not yet been established between the research team and community members at the time of data collection.

\section{Jurisdictional Issues}

Jurisdictional issues around health service delivery presented its own challenges. Adjacent to four of the Swampy Cree First Nations communities, are Métis communities. While the 
geographical locale itself is not an issue, these two different Aboriginal communities are serviced by different levels of government in terms of health. The federal department provides health services to First Nations communities while the provincial government is responsible for the health needs of the Métis communities. Consequently, there are provincially-organized nursing stations on the Métis side of the communities that are used by the First Nations segment of the population as well. When conducting the qualitative interviews, some of the key people we wished to interview were healthcare professionals who worked in the nursing stations and health centres. Additional effort was required by the interviewers to reach these participants.

\section{Remoteness}

The remoteness of some of the communities also presented a challenge for visiting the communities to conduct the interviews. Extensive travel by air and land was required on the part of the researchers in order to reach these communities.

\section{Experience of the Interviewers}

Finally, another challenge faced by the researchers conducting the interviews was the feeling of helplessness. Suicide is a sensitive topic, and a very personal and emotional one for some. Due to the nature of the interview questions, participants on occasion disclosed very personal information of their life experiences and current life situations. Interviewers grappled with feelings of helplessness and despair as a result of being unable to provide timely and appropriate counseling for participants, rather than referrals to local mental health therapists. Several of the interviewers did however offer a listening ear to some participants, which seemed to provide some solace. It was appreciated that feelings of despair and helplessness must be common experiences in some First Nations communities. Interviewers also initially met at the end of each day to debrief and document their feelings and concerns, which was a helpful process.

\section{Lessons Learned}

The Sharing Circle

During the group sessions at our first annual conference, we as researchers, attempting to conduct the proceedings in a culturally-appropriate manner, offered each of the three groups the option of using a sharing circle format instead of the typical focus group format. A sharing circle is an Aboriginal oral tradition used as a method of sharing stories and information (Berthelett et al. 2001). In a sharing circle all members are given equal opportunity and there is an expectation for all members to share, including the researchers in this instance (Nabigon et al. 1999). The sharing circle format also adheres to traditional spontaneity in questioning and discussion (Berthelett et al. 2001), whereas in a focus group the facilitator asks the questions and participants give their responses, with very little input by the facilitator (Krueger and Casey 2000). Lavallée (2009) suggests that while sharing circles and focus groups are similar, there is one distinct difference in that sharing circles have sacred meaning within many Indigenous cultures and may result in the growth and change of individual participants. While our intentions as researchers were to be helpful, in 
this case it would seem we were somewhat unaware of what a sharing circle actually entailed. A participant commented later through a letter to the research team:

This [sharing circle format] is a useful method of facilitating discussion on a subject as difficult as suicide.... I would suggest that it would be helpful in the future if the researchers would participate in the discussions. Sharing circles depend on trust. One of the ways that this is achieved is by honest sharing and discussion from all members of the circle. The researchers in this conference did not share openly although the expectations were that we would. This raises an issue of trust and lack of it.

What we learned from this experience was two-fold. First, that we as Western researchers still have much to learn about the Aboriginal culture and way of doing things, and second, that if we are truly engaged in a partnership endeavor, we may also be required to share of ourselves from time to time. Nevertheless, we needed to provide a response to this comment that would be acceptable from both the scientific research process and Aboriginal perspective. After discussion with our First Nations facilitator, we acknowledged that in hindsight, the sharing circle format appeared not to have been a good suggestion. In future, the focus group format would be explained more clearly in that participants are not expected to share if they are not comfortable doing so, highlighting the difference from a sharing circle. We also explained that as qualitative researchers, psychiatrists and clinical psychologists, we are trained to be listeners and are encouraged not to have significant input into the discussion so as not to influence responses of participants. At the same time, while we did not initially realize the cultural issues around our lack of sharing during the talking circles, in future researchers might prepare themselves to participate more fully in the sharing circle format and the cultural practices of participants to establish mutual trust.

\section{The Definition of "Researcher" Within the Participatory Action Research (PAR) Context}

Given the experiences of the research team during the interviewing process and sharing circle as presented above, a discussion on the role of researcher within the PAR framework may be helpful. Pyrch and Castillo (2001), provide a commentary of lessons learned in their work with Indigenous populations. The authors outline a total of seven lessons with regard to PAR. They indicate that PAR invites alternative perspectives to share, that it "is based on trust" and that it "demands time" (p 384). As a research team working with the Swampy Cree communities and Tribal Council, these are also lessons we have learned, particularity with regards to time and trust. While the broader project has been able to develop some of these attributes, it has been more difficult to establish them on a one-time meeting such as during the sharing circle or qualitative interviews.

\section{Knowledge Translation}

Knowledge translation activities are fundamental as one of the tenets of participatory research (Reason and Bradbury 2001) and are particularly valuable when partnering with Aboriginal groups (Elias and O'Neil. 2006). The CIHR guidelines for research with Aboriginal communities state that regular status project updates should be provided to communities (CIHR 2007). The Swampy Cree suicide prevention team has provided project progress information to the Swampy Cree communities, through update letters to health directors, chief and councils, and a newsletter for community members. Furthermore, the broader provincial and national health research community has been updated via radio and television interviews and local and national conferences. A Website has been developed 
for the project and will continue to be updated (www.suicideresearch.ca). It is also our experience in working with the First Nations communities, that there is a desire for information to be disseminated across various sectors within the communities such as education, health and band administration.

\section{Individual Versus Focus Group Interviews for Research on Suicide}

A final lesson learned thus far is that of conducting focus groups versus individual interviews for research on suicide. During visits to the first pair of Swampy Cree communities we chose to conduct focus groups with four to eight people per group. For some groups, this was a very positive experience. For others, the nature of the focus group resulted in the sharing of very emotional and personal information such that it created a ripple effect of despair within the group. After consultation with the research team psychiatrists, it was decided that all future interviews would be conducted on an individual basis to avoid recurrence of these types of situations.

The collaboration between Indigenous communities and academic researchers is a process that involves learning and sharing of knowledge in a bidirectional manner as well as other key elements. Research teams who have collaborated with Indigenous groups in New Zealand (Tipa et al. 2009) and Australia (Pyett et al. 2009) on health research initiatives, have reported both similar and additional lessons learned such as flexibility, communication choices, the need to allow for extra time to develop trust and the importance of educating ourselves as researchers about the Aboriginal people and communities we are working with.

\section{Conclusion}

While the process employed for this study may not be unique in regards to Aboriginal health research, it is to our knowledge the first of its kind for a suicide prevention project in Manitoba and perhaps Canada. The knowledge gained from the experiences of and lessons learned by our research team may assist and be applicable to other indigenous/academic researcher collaborations in a broader international context. It is our hope to continue to listen, to learn from, and to work with the Swampy Cree communities and tribal council to improve well-being and aid in the development of community and regional mental health and suicide prevention strategies that will be effective, sustainable and beneficial to all.

Acknowledgements We would like to acknowledge the other members of the Swampy Cree Suicide Prevention Team* who assisted with the development of the project and qualitative data collection. Funding for the project was provided by the Canadian Institutes of Health Research.

Conflict of Interest The authors have no financial relationship with the organization that sponsored the research and have full control of all primary data. We agree to allow the International Journal of Mental Health and Addiction to review our data if requested.

\section{References}

Aboriginal Healing Foundation. (2007). Suicide among Aboriginal people in Canada. Ottawa: Aboriginal Healing Foundation. 
Assembly of Manitoba Chiefs (AMC). (2009). Manitoba First Nations communities. Retrieved January 13, 2009 from http://www.manitobachiefs.com/amc/communities.htm.

Berthelett, G., Raftis, Y., \& Henderson, G. (2001). The sharing circle. a culturally appropriate format for a focus group? The Aboriginal Nurse, 16(2), 17-18.

Boothroyd, L. J., Kirmayer, L. J., Spreng, S., Malus, M., \& Hodgins, S. (2001). Completed suicide among the Inuit of northern Quebec, 1982-1996: a case control study. Canadian Medical Association Journal, 165(6), 749-755.

Canadian Institutes of Health Research (CIHR). (2007). CIHR guidelines for health research involving aboriginal people. Ottawa: Canadian Institutes of Health Research.

Chandler, M. J., \& Lalonde, C. (1998). Cultural continuity as a hedge against suicide in Canada's First Nations. Transcultural Psychiatry, 35(2), 191-219.

Chandler, M. J., \& Proulx, T. (2006). Changing selves in changing worlds: youth suicide on the fault-lines of colliding cultures. Archives of Suicide Research, 10(2), 125-140.

Constitution Act. (1982). Schedule B, Part II: Rights of Aboriginal Peoples of Canada. Canada: Department of Justice. Retrieved September 21, 2005 from http://laws.justice.gc.ca/en/const/annex e.html\#II.

Cornwall, A., \& Jewkes, R. (1995). What is participatory research? Social Science and Medicine, 41(12), $1667-1676$.

Denzin, N. K., \& Lincoln, Y. S. (2008). Critical methodologies and Indigenous inquiry. In N. K. Denzin, Y. S. Lincoln \& L. T. Smith (Eds.), Handbook of critical and Indigenous methodologies (pp. 1-20). Los Angeles: Sage.

Elias, B., \& O’Neil, J. (2006). The Manitoba First Nations Centre for Aboriginal Health Research: knowledge translation with Indigenous communities. Healthcare Policy, 1(1), 44- 49.

Elias, B., O’Neil, J., \& Sanderson, D. (2004). The politics of trust and participation: a case study in developing First Nations and university capacity to build health information systems in a First Nations context. Journal of Aboriginal Health, 1(1), 68-78.

First Nations and Inuit Regional Health Survey National Steering Committee. (2000). First Nations and Inuit regional health survey: National report 1999. St. Regis: First Nations and Inuit Regional Health Survey National Steering Committee.

Grande, S. (2008). Red pedagogy. The un-methodology. In N. K. Denzin, Y. S. Lincoln \& L. T. Smith (Eds.), Handbook of critical and Indigenous methodologies (pp. 1-20). Los Angeles: Sage.

Grassroots News. (2008, June 17).

Grassroots News. (2008, September 9).

Grossman, D. C., Milligan, B. C., \& Deyo, R. A. (1991). Risk factors for suicide attempts among Navajo adolescents. American Journal of Public Health, 81(7), 870-874.

Health Canada. (2003). Acting on what we know: Preventing youth suicide in First Nations. Ottawa: Advisory Group on Suicide Prevention.

Health Canada. (2007). National Aboriginal youth suicide prevention strategy. Program framework. Ottawa: First Nations, Inuit and Aboriginal Health.

Indian and Northern Affairs Canada (INAC). (2009). Tribal council detail. Retrieved January 6, 2009 from http://pse5-esd5.ainc-inac.gc.ca/fnp/Main/Search/TCMain.aspx?TC_NUMBER=1005\&lang=eng.

Katz, L., Elias, B., O’Neil, J., Enns, M., Cox, B. J., Belik, S., et al. (2006). Aboriginal suicidal behaviour research: from risk factors to culturally-sensitive intervention. Journal of the Canadian Academy of Child and Adolescent Psychiatry, 15(4), 159-167.

Kirmayer, L. J., Boothroyd, L. J., \& Hodgins, S. (1998). Attempted suicide among Inuit youth: psychosocial correlates and implications for prevention. Canadian Journal of Psychiatry, 43(8), 816-822.

Kirmayer, L. J., Boothroyd, L. J., Laliberte, A., \& Laronde Simpson, B. (1999). Suicide prevention and mental health promotion in First Nations and Inuit communities. Culture \& Mental Health Research Unit, Report No. 9. Montreal, QC: Institute of Community \& Family Psychiatry, Sir Mortimer B. Davis Jewish General Hospital.

Kirmayer, L. J., Brass, G. M., \& Tait, C. L. (2000). The mental health of Aboriginal peoples: transformations of identity and community. Canadian Journal of Psychiatry, 45(7), 607-616.

Krefting, L. (1991). Rigor in qualitative research: the assessment of trustworthiness. American Journal of Occupational Therapy, 45, 214-222.

Krueger, R. A., \& Casey, M. A. (2000). Focus groups. A practical guide for applied research (3rd ed.). Thousand Oaks: Sage.

Lavallée, L. F. (2009). Practical application of an Indigenous research framework and two qualitative Indigenous research methods: sharing circles and Anishnaabe symbol-based reflection. International Journal of Qualitative Methods, 8(1), 21-40.

LivingWorks Education Inc. (1991). Programs. Retrieved January 7, 2009 from http://www.livingworks.net/ LW_Prgrms.php. 
Lucasey, B. (2000). Qualitative research and focus group methodology. Orthopaedic Nursing, 19, 54-56.

Malchy, B., Enns, M. W., Young, T. K., \& Cox, B. J. (1997). Suicide among Manitoba's Aboriginal people, 1988 to 1994. Canadian Medical Association Journal, 156(8), 1133-1138.

Manitoba Health Living. (2008). Reclaiming hope: Manitoba's youth suicide prevention strategy. Winnipeg: Manitoba Government.

Mann, J. J., Apter, A., Bertolote, J., Beautrais, A., Currier, D., Haas, A., et al. (2005). Suicide prevention strategies: a systematic review. Journal of the American Medical Association, 294(16), 2064-2074.

Masecar, D. (2007). What is working, what is hopeful...? Supporting community-based suicide prevention strategies within Indigenous communities. Ottawa: First Nations Inuit Health Branch.

Mignone, J., \& O’Neil, J. (2005). Social capital and youth suicide risk factors. Canadian Journal of Public Health, 96(Suppl 1), S51-S54.

Morse, J. M., \& Richards, L. (2002). Readme first for a user's guide to qualitative methods. Thousand Oaks: Sage.

Nabigon, H., Hagey, R., Webster, S., \& MacKay, R. (1999). The learning circle as a research method: the trickster and windigo in research. Native Social Work Journal, 2(1), 113-137.

National Aboriginal Health Organization (NAHO). (2005). Assessment and planning tool kit for suicide prevention in First Nations communities. Ottawa: National Aboriginal Health Organization.

O’Neil, J., Reading, J. R., \& Leader, A. (1998). Changing the relations of surveillance: the development of a discourse of resistance Aboriginal epidemiology. Human Organization, 57(2), 230-237.

O’Neil, J., Elias, B., \& Wastesicoot, J. (2005). Building a health research relationship between First Nations and the University in Manitoba. Canadian Journal of Public Health, 96(Suppl 1), S9-S12.

Patton, M. Q. (2002). Qualitative research and evaluation methods (3rd ed.). Thousand Oaks: Sage.

Pyett, P., Waples-Crowe, P., \& vander Sterren, A. (2009). Engaging with Aboriginal communities in an urban context: some practical suggestions for public health researchers. Australian and New Zealand Journal of Public Health, 33(1), 51-54.

Pyrch, T., \& Castillo, M. T. (2001). The sights and sounds of Indigenous knowledge. In P. Reason \& H. Bradbury (Eds.), Handbook of action research, participative inquiry and practice (pp. 379-385). London: Sage.

Reason, P., \& Bradbury, H. (2001). Introduction: inquiry and participation in search of a world worth of human aspiration. In P. Reason \& H. Bradbury (Eds.), Handbook of action research, participative inquiry and practice (pp. 1-14). London: Sage.

Royal Commission on Aboriginal Peoples (RCAPa). (1995). Choosing life: Special report on suicide among Aboriginal people. Ottawa: Canadian Government Publishing.

Royal Commission on Aboriginal Peoples (RCAPb). (1995). Suicide among Aboriginal people: Royal commission report. Ottawa: Library of Parliament.

Sareen, J., Munro, G., Campeau, M., Elias, B., \& the Swampy Cree Suicide Prevention Team. (2008). Building important partnerships in order to prevent suicide among First Nations [Letter to the editor]. Grassroots News, September 9.

Schnarch, B. (2004). Ownership, control, access, and possession (OCAP) or self-determination applied to research. Journal of Aboriginal Health, 1(1), 80-95.

Sigurdson, E., Staley, D., Matas, M., Hildaho, K., \& Squair, K. (1994). A five-year review of youth suicide in Manitoba. Canadian Journal of Psychiatry, 39(8), 397-403.

Statistics Canada. (2003). 2001 Census: Analysis series. Aboriginal peoples of Canada: A demographic profile. Cat. No. 96F0030XIE2001007. Retrieved July 1, 2005 from http://www12.statcan.ca/english/ census01/products/analytic/companion/abor/canada.cfm.

Swampy Cree Tribal Council. (2009). Retrieved January 13, 2009 from http://www.swampycree.com/.

Tipa, G., Panelli, R., \& Moeraki Stream Team. (2009). Beyond 'someone else's agenda': an example of indigenous/academic research collaboration. New Zealand Geographer, 65, 95-106.

Trimble, J. E. (2008). Commentary: no itinerant researchers tolerated: principled and ethical perspectives and research with North America Indian communities. Ethos, 36(3), 380-383.

Wexler, L., \& Goodwin, B. (2006). Youth and adult community member beliefs about Inupiat youth suicide and its prevention. International Journal of Circumpolar Health, 65(5), 448-458.

White, J. (2005). Preventing suicide in youth: Taking action with imperfect knowledge. Vancouver: Children's Mental Health Policy Research Program University of British Columbia.

White, J., \& Jodoin, N. (2003). Aboriginal youth: A manual of promising suicide prevention strategies. Calgary: Centre for Suicide Prevention.

World Health Organization (WHO). (2000). Preventing suicide. A resource for primary health care workers. Geneva: Mental and Behavioural Disorders, Department of Mental Health, WHO. 